\title{
An Evaluation of an Abstinence-Only Sex Education Curriculum: An 18-Month Follow-up
}

\author{
George Denny, Michael Young
}

\begin{abstract}
The article examines the results from an 18-month follow-up evaluation of an abstinence education curriculum series Participants were students from 15 school districts recruited to participate in the project. The intervention was the Sex Can Wait curriculum series, consisting of upper elementary, middle school, and high school components. The 5-week curriculum was implemented by teachers who had participated in a special teacher training workshop. Both intervention and comparison students were surveyed before and after the curriculum intervention and at 18-month follow-up. Results indicated short-term effects as follows. Upper elementary intervention students indicated higher level of knowledge, more hopefulness for the future, and greater self-efficacy than did the comparison group. Middle school intervention students did not differ from comparison students. High school intervention students reported lower participation rates than the comparison group students in sexual intercourse (ever and last month), a more positive attitude toward abstinence and a greater intent to remain abstinent. Long-term (18 month) benefits were noted as follows: upper elementary intervention students had greater knowledge and were less likely than comparison students to report participation in sexual intercourse in the last month. Middle school intervention students were less likely than comparison students to report participation in sexual intercourse ever and sexual intercourse in the last month. High school intervention students evidenced greater knowledge and greater intent to remain abstinent than did comparison students. Results indicate that the program did have some positive benefits that should be considered by those interested in abstinence education programming. (J Sch Health. 2006;76(8):414-422)
\end{abstract}

$\mathbf{T}^{\mathrm{h}}$ here has long been controversy in this country about the implementation of school-based sexuality education. ${ }^{1}$ In recent years, however, the controversy has centered on abstinence education. Federal involvement in abstinence education began under President Reagan with the Adolescent Family Life Act administered by the Office of Adolescent Pregnancy Programs (OAPP). In 1996, a provision was added to the Welfare Reform Act that blockgranted abstinence education funds to states and introduced a federal "a-h" definition of abstinence education. The definition emphasized teaching abstinence from all sexual activity except within the context of marriage. The definition also applied to OAPP grantees. More recently, abstinence education grants have been awarded directly to community groups under the Special Projects of Regional and National Significance, a program that in 2005 became the Community Based Abstinence Education Program. Currently, substantial amounts of federal dollars are going to support abstinence education programs.

Critics of abstinence education programs have indicated that such programs are ineffective in reducing sexual behavior among teens. A review of published evaluations of abstinence education curricula indicates, however, that rather than research showing that abstinence programs are not effective, there are simply few studies that have examined the impact of abstinence education on student sexual behavior. $^{2}$ In fact, of the 46 curricula listed in the Abstinence Clearinghouse Directory of Abstinence Resources, ${ }^{3}$ no published evaluations exist that examine the effects of any of them on sexual behavior. Given the funding emphasis that has been placed on abstinence education, it is important that these programs be evaluated. Published evaluations

George Denny, PhD, Professor, Educational Foundations (gdenny@uark. edu), 231 Graduate Education, University of Arkansas, Fayetteville, AR 72701; and Michael Young, PhD, University Professor, Health Sciences, (meyoung@uark.edu), Health Education Projects Office, University of Arkansas, Fayetteville, AR 72701. that do examine the effects of abstinence programs on measures of sexual behavior are summarized below.

In 1990, 2 different evaluations of the Success Express abstinence education program were published. ${ }^{4,5}$ Both studies used a quasi-experimental design with a pretest, posttest, and 6-week follow-up of both intervention and comparison groups. Researchers examined the impact of the program on the initiation of sexual intercourse and found that the program produced no differences between the intervention and comparison groups relative to this variable. It should come as no surprise, however, that these studies, with a short follow-up period produced no effect. In fact, the first published evaluation of Reducing the Risk, ${ }^{6}$ one of the most frequently cited evaluations of a sexuality education program, found no effect due to the program at 6-month or 12-month follow-up but did find an effect at the 18-month follow-up. ${ }^{7}$ The longer follow-up period gave students more opportunity to begin having sex, and significantly more students in the comparison group did so than did the intervention group. This long-term follow-up was lacking in the Success Express studies.

Evaluations of Project Taking Charge, a curriculum from the American Association of Family and Consumer Sciences, were published in $1991^{8}$ and in $1993 .{ }^{9}$ The first article examined pretest-posttest differences, and the second article examined the 6-month follow-up data for this curriculum. At 6-month follow-up, the comparison group subjects were more likely $(\mathrm{p}=.051)$ than the intervention subjects to report initiation of intercourse.

St. Pierre et al. ${ }^{10}$ evaluated the impact of the Stay Smart curriculum. These researchers did conduct a long-term evaluation, surveying students at 3-, 15-, and 27-month followups. Students were assigned to the basic program, the program plus booster, or a comparison group. For students who were virgins at pretest, there was no effect on the combined measure at posttest. For students who were nonvirgins at pretest, there was no effect at posttest, except at 27 months there was an effect on the frequency of intercourse 
for the basic program group but not for the group that received the basic program plus the booster. One would expect that the basic program plus the booster program would produce improvements of at least the same degree as the basic program alone. This did not happen.

In 1997, Kirby et al. published an evaluation of Education Now and Babies Later, an abstinence program that included the Postponing Sexual Involvement curriculum. ${ }^{11}$ This study included a large sample size, random assignment, and long-term follow-up. Results indicated that the program had no impact on initiation of intercourse (in the previous 3 or 12 months), number of sexual partners, use of condoms or birth control pills, or pregnancy (except in the teen-led program, where program participants were statistically more likely to be involved with a pregnancy).

Barnett and Hurst ${ }^{12}$ published an evaluation of the Walk of Life abstinence education program that involved 2 separate studies. Study $1(n=217)$ employed a pretest-posttest design, with no comparison group. Results actually showed an increase in sexual behavior, not that surprising since there was no control for maturation. In study 2, 86 eighth graders were assigned to multiple sections of health. The program was implemented in the fall, with students scheduled to take a health class in the spring serving as the control group. Study 2 found no impact (positive or negative) on behavior at posttest.

One of the interesting things about this evaluation was the behavior measure used in both studies. It involved a 10-item scale with each item rated on a scale of 1 (never done) to 5 (10 or more times). Behaviors listed ranged from "kissing and hugging" to "touching beneath the waist under clothing." Students were not asked about participation in sexual intercourse because school officials would not give approval. Many studies of adolescent sexual behavior ask only about participation in sexual intercourse, leaving a gap in our knowledge regarding other sexual behaviors in which young people might participate. Thus, the authors are to be commended for attempting to measure behaviors other than intercourse. Yet, it is unclear what this scale actually measures. Of the 10 behaviors comprising the scale, the authors only provided the 2 extremes, and neither of these, nor presumably the remaining 8, poses a direct risk of pregnancy or sexually transmitted disease.

Jemmott et al. ${ }^{13}$ examined the impact of the Making a Difference curriculum. They found that young people who participated in the abstinence group were less likely to report having sexual intercourse in the 3 months after the intervention than were those in the control group. This difference no longer existed at the 6- and 12-month follow-ups. At 12-month follow-up, however, adolescents in the abstinence program reported more frequent condom use than did those in the control group. This program is not typical of the abstinence education curricula used in federally funded programs because it advocates abstinence from risky sexual behaviors (ie, sexual intercourse, oral sex, and anal sex) but not necessarily from other types of sexual activity.

The abstinence-only sex education curriculum for which there are the most published evaluations is the Sex Can Wait curriculum series. ${ }^{14-16}$ Four of the 5 published evaluation articles included an examination of the impact of the curricula on behavioral measures. None of these evaluations included any type of long-term follow-up. Young et al. ${ }^{17}$ evaluated the impact of Living Smart (now the middle school component of Sex Can Wait) and found that students who were taught the curriculum as a part of their health education class were less likely to report participation in sexual intercourse in the last month than students who were in a health education class that did not receive the curriculum, or no-health comparison students.

The intervention that Goldfarb et al. ${ }^{18}$ evaluated consisted of the upper elementary component of Sex Can Wait taught to sixth graders, the middle school component taught to seventh graders, and activities from Abstinence: Pick \& Choose Activities ${ }^{19}$ taught to eighth graders. At posttest, immediately after completion of the 5-week program, researchers found that compared to students at comparison schools, students at intervention schools were less likely to report sexual intercourse ever and sexual intercourse in the last month.

Denny et al. ${ }^{20}$ examined the impact of all 3 components of the curriculum series, comparing intervention schools to comparison schools. No behavioral questions were asked of upper elementary students. The researchers indicated that at posttest, immediately after completion of the 5-week curriculum, the behavioral trends (for sexual intercourse ever and last month) were in the desired direction for both the middle school and high school students. These trends, however, were not statistically significant.

Denny et al. ${ }^{21}$ again evaluated the impact of all 3 components of the curriculum. This time at posttest, immediately after completion of the 5-week curriculum, there were significant differences at the high school level between intervention and comparison students in regard to sexual intercourse (both ever and last month). Students who participated in the curriculum were less likely to report participation in the behaviors than were comparison students.

In spite of no follow-up data, the published studies evaluating Sex Can Wait have shown, in a number of instances, positive behavioral effects. This article examines the results from an 18-month follow-up evaluation of the Sex Can Wait curriculum series.

\section{Sample}

\section{METHOD}

Participants for the study were students from 15 school districts recruited to participate in the project. Schools were divided by grade level into treatment grade levels that taught the Sex Can Wait curriculum and comparison grade levels that taught their regular curriculum (health education with a sex education component). The program was offered at 3 levels: upper elementary (grade 5 or 6), middle school (grade 7 or 8), and high school (grade 9 or above). Schools were counterbalanced so data were collected at all grade levels from both the treatment group and the comparison group. Because these schools had existing sexuality education programs, the study compared the effects of the Sex Can Wait curriculum to "current practice" rather than true "control" conditions. The study design and protocol were reviewed and approved by the university's institutional review board.

To be included in the analysis, individuals had to have a matching pretest and 18-month follow-up measure. Across the 3 levels of the curriculum, of the 1421 students who took the pretest, $1195(84 \%)$ had a matching posttest score; $680(48 \%)$ had a matching follow-up score. 


\section{Curriculum}

The abstinence-only sex education curriculum intervention was the Sex Can Wait curriculum series, consisting of upper elementary, ${ }^{16}$ middle school, ${ }^{15}$ and high school ${ }^{14}$ components. The second author of this article is a coauthor of all 3 components of the curriculum series. The program is a 5-week, abstinence education curriculum, consisting of 23 lessons at the upper elementary level and 24 lessons at both the middle school and high school levels. The 3 main divisions of each level of the curriculum are (a) Knowing Myself (self-esteem, reproductive anatomy and physiology, changes associated with puberty, values and decisionmaking skills), (b) Relating to Others (development and enhancement of communication skills), and (c) Planning My Future (goal setting and life planning).

Each lesson includes a lesson overview, behavioral objectives, a time estimate, and teacher direction as to preparation and materials needed. Each activity includes the actual words the teacher could use to introduce the activity, specific procedures for conducting the activity, and the words to be used in closing the activity. Handouts and transparencies are included. The curriculum includes a number of parent-child homework activities, guidelines and tips for teacher implementation, and information for parents regarding communication with their children about sex and sexuality.

There are no lessons dealing with contraceptives. Teachers are encouraged to provide an environment in which students will want to ask questions and to answer student questions on topics not specifically addressed in the curriculum. They are given guidelines for doing so. All 3 levels of the series were revised and reviewed for compliance with the welfare reform definition of abstinence education by the OAPP and approved for use in projects funded by that agency.

\section{Teacher Training}

The curriculum series was implemented by teachers who had participated in a 3.5-day training workshop. The workshop helped teachers understand the rationale for the curriculum and allowed them to see lessons from the curriculum modeled by skilled trainers, to present a lesson themselves, and to learn and practice a model for dealing with controversial issues and student questions.

\section{Testing Instruments}

The process evaluation involved using teacher reaction sheets and teacher checklists. The evaluation of the impact of the program on student outcomes involved the use of a student self-report questionnaire. The questionnaire for students in grade 7 and lower included 2 questions addressing sexual behavior. The questionnaire for students in grade 8 and above included 5 additional sexual behavioral questions. The questionnaire was adapted from one used by Young et al. ${ }^{17}$

The questionnaire was a 78-item questionnaire that consisted of 20 knowledge items based on information in the Sex Can Wait curriculum (alpha $=.68$ ); a 16-item attitude scale (alpha $=.82$ ); the 17-item Hopelessness Scale for Children (HSC) (alpha $=.62$ ); a 6-item scale dealing with initiation and persistence (alpha $=.57$ ); a 6-item scale that asked about student decision-making behaviors (general decision making rather than sexual decision making, or decision making in the context of relationships) (alpha $=.59) ; 3$ items representing behavioral intent that were measured on a scale ranging from $1=$ definitely will not to $5=$ definitely will, which asked students about the chance that they would have sexual intercourse in (a) the next year, (b) before finishing high school, and (c) before marriage (alpha $=.82$ ); and 2 yes/ no items dealing with whether students had ever participated in sexual intercourse and whether they had done so in the last 30 days.

The HSC $^{22}$ was designed to measure participants' degree of positive or negative expectations for the future. This measure consisted of 17 statements to which students responded either "true" or "false." The HSC was chosen because of the belief that if adolescents have a positive view of the future they would be empowered to act in their own best interest, in this case, avoid the risks associated with early sexual intercourse. Previous studies in which the HSC has been used have reported coefficient alpha levels as high as .97 (child psychiatric inpatients) ${ }^{23}$ and as low as .69 (children and adolescents with mental retardation or learning disability). ${ }^{24}$

The 6 items dealing with initiation and persistence (efficacy expectations) were taken from the general selfefficacy portion of the self-efficacy scale. ${ }^{25}$ Bandura $^{26}$ has indicated the important role of expectations of self-efficacy in initiating and persisting in a behavior. Thus, this measure was chosen because of the belief, based on Bandura's work, that adolescents who score high on this construct will make and maintain a commitment to abstain from early sexual intercourse. The researchers who constructed and validated the scale reported a coefficient alpha of .86 for the general self-efficacy subscale but did not report on the psychometrics associated with initiation and persistence. ${ }^{25}$ To examine the factor structure of this scale, a principal components analysis with Varimax rotation was conducted and 2 factors were identified. The factors corresponded to positively and negatively worded items (ie, positive-when I make plans, I am certain I can make them work. Negative-when I set important goals for myself, I rarely achieve them). All items loaded at .62 or above. Both factors reflected acquiescence bias, or the tendency to agree with statements in both directions, on the part of some of the students. Cronbach's alpha for the scale was .57 .

For the behavioral intent questions and the 2 questions regarding actual sexual behavior, the suggestion of Howard (M. Howard, personal communication, Bethesda, Md, October 15, 1998), author/evaluator of the Postponing Sexual Involvement curriculum, was followed. She indicated that since abstinence curricula encouraged young people to abstain from sexual involvement, evaluators of these types of curricula might do well to frame behavioral questions relative to abstinence behavior (Have you been sexually abstinent in the last 30 days?) rather than sexual behavior (Have you had sexual intercourse in the last 30 days?). Thus, the 2 behavior questions asked of students at all 3 levels of the curriculum were worded as follows: (1) "To this point in your life have you remained sexually abstinent?" ('yes' means you have not experienced sexual intercourse. 'no' means you have had sexual intercourse). Sexual intercourse means the male's penis is in the female's vagina." (2) "Have you abstained from sexual 
intercourse during the last month?" ('yes' means you have not had sexual intercourse in the last month. 'no' means you have had sexual intercourse in the last month").

The 3 behavioral intent questions asked about abstinence "during the next year," "from now until you finish high school," and "from now until you are married" and were framed "What is the chance you will remain abstinent from sexual intercourse ..." Students responded on a 5-point Likert-type scale from "definitely will not" to "definitely will." The 3 time periods, next year, finish high school, and marriage, have been used in previous research. ${ }^{20}$ Framing the questions to emphasize abstinence from the behavior was again consistent with suggestions by Howard (M. Howard, personal communication, Bethesda, Md, October 15, 1998).

\section{Procedure}

Students voluntarily, with written parental consent, completed the questionnaire on a pretest basis, in their regular classroom setting, prior to the implementation of the curriculum. Students' scan sheets were coded to match an individual student's responses from different testing times. A member of the research team read the questionnaire to the upper elementary students. A copy of the questionnaire was also projected on a screen using an overhead projector. Middle school and high school students were given a questionnaire booklet. They marked answers on their scan sheets at their own pace.

To maximize the validity of these self-report data, the researcher emphasized that (a) all individual responses were confidential and would not be revealed to parents or school personnel, (b) students were to keep their eyes on their own work and not to discuss any of the questions with other students, and (c) students were told they had the right to "pass" on any question that they did not wish to answer. They were encouraged to answer all questions, with emphasis placed on the importance of honest answers. Following the pretest, the Sex Can Wait curriculum series was implemented in all school districts. At each school, the curriculum was taught by a teacher who had been trained in the use of the curriculum. After completion of the program, all students were again surveyed, using the same instrument and following the same protocol. They were surveyed again a third time approximately 18 months following the posttest.

\section{Data Analysis}

Data were analyzed using SPSS procedures. Analyses were conducted with and without subjects who had logical inconsistencies in their responses. Results, relative to which variables were found to be statistically significant, did not change.

The research design for the study was a quasi-experimental, pretest-posttest-follow-up comparison group design. Analyses of covariance used the pretest as the covariate and compared adjusted means for the 2 groups (treatment and comparison) for all interval-level variables. Logistic regression was used to analyze data for the 2 behavioral questions to determine whether group membership (treatment-comparison) had a significant relationship with sex- ual behavior at posttest and at follow-up, when controlling for virgin status and behavioral intent at pretest.

\section{RESULTS}

Fidelity of Implementation

Teachers using the Sex Can Wait curriculum series were asked after each lesson to check the activities and objectives they addressed in their instruction. Comparison group teachers were given a list of the instructional topics and asked to indicate the topics they addressed in their classroom. Treatment group teachers covered most of the lessons in the curriculum, but the comparison group teachers also addressed many of the same topics.

Project staff members visited schools, observed classes, and conducted informal interviews to see if there were problems implementing the curriculum. Staff believed that the teacher reports of content coverage were substantially correct. Teachers did not address every topic and faced the interruptions that are a part of school life and that make complete coverage of content difficult.

\section{Upper Elementary Student Outcomes}

Matched pretest-posttest data were obtained from 301 students, and matched pretest-18-month follow-up data were obtained from 196 students. The pretest-posttest students included 189 whites (64.5\%), 91 African Americans (31.1\%), 7 Hispanics (2.4\%), 4 Asian Americans (1.4\%), and 2 American Indians $(.7 \%)$. There were 8 students who did not indicate racial/ethnic membership (Table 1).

Results of the analysis of covariance indicated significant posttest differences $(p<.05)$ between the Sex Can Wait treatment group and the comparison group relative to knowledge, hopelessness, and self-efficacy (Table 2). The Sex Can Wait group had a higher level of knowledge, indicated more hopefulness for the future, and greater self-efficacy than did the comparison group. There were no differences at posttest between the treatment group and the comparison group relative to behavior (Table 3). At 18-month follow-up, there were significant differences $(\mathrm{p}<.05)$ between the Sex Can Wait treatment group and

\section{Table 1 Number and Percents of Students in the Study*}

\begin{tabular}{|c|c|c|c|c|c|c|}
\hline \multirow[b]{2}{*}{ School/Grade Level } & \multicolumn{2}{|c|}{ Pretest } & \multicolumn{2}{|c|}{ Posttest } & \multicolumn{2}{|c|}{ Follow-Up } \\
\hline & $\mathbf{N}$ & $\%$ & $\mathbf{N}$ & $\%$ & $\mathbf{N}$ & $\%$ \\
\hline \multicolumn{7}{|l|}{ Comparison schools } \\
\hline Upper elementary & 98 & 100 & 79 & 81 & 42 & 43 \\
\hline Middle school & 372 & 100 & 319 & 86 & 109 & 29 \\
\hline High school & 111 & 100 & 92 & 83 & 76 & 68 \\
\hline \multicolumn{7}{|l|}{ Treatment schools } \\
\hline Upper elementary & 278 & 100 & 222 & 80 & 154 & 55 \\
\hline Middle school & 326 & 100 & 288 & 88 & 131 & 40 \\
\hline High school & 226 & 100 & 195 & 86 & 168 & 74 \\
\hline
\end{tabular}

${ }^{\star} \mathrm{N}=376$ upper elementary, 698 middle level, 337 high school. 


\begin{tabular}{|c|c|c|c|c|c|c|c|c|c|c|}
\hline \multirow[b]{2}{*}{ Variable } & \multicolumn{5}{|c|}{ Comparison Group } & \multicolumn{5}{|c|}{ Sex Can Wait } \\
\hline & Pretest & $\mathbf{n}$ & Posttest & $\mathbf{n}$ & Follow-up & Pretest & $\mathbf{n}$ & Posttest & $\mathbf{n}$ & Follow-up \\
\hline \multicolumn{11}{|c|}{ Knowledge (percent correct) } \\
\hline \multicolumn{11}{|c|}{ Upper elementary } \\
\hline Mean & 41 & \multirow[t]{2}{*}{79} & 43 & \multirow[t]{2}{*}{38} & 50 & 50 & \multirow[t]{2}{*}{222} & 62 & \multirow[t]{2}{*}{158} & 62 \\
\hline SD & 14 & & 17 & & 15 & 17 & & 15 & & 15 \\
\hline \multicolumn{11}{|c|}{ Middle school } \\
\hline Mean & 60 & \multirow[t]{2}{*}{319} & 61 & \multirow[t]{2}{*}{109} & 64 & 58 & \multirow[t]{2}{*}{287} & 61 & \multirow[t]{2}{*}{131} & 65 \\
\hline SD & 16 & & 16 & & 18 & 17 & & 21 & & 16 \\
\hline \multicolumn{11}{|c|}{ High school } \\
\hline Mean & 68 & \multirow[t]{2}{*}{92} & 68 & \multirow[t]{2}{*}{76} & 72 & 67 & \multirow[t]{2}{*}{195} & 71 & 167 & 64 \\
\hline SD & 15 & & 15 & & 12 & 13 & & 18 & & 19 \\
\hline Attitude (1 & & & & & & & & & & \\
\hline Upper el & & & & & & & & & & \\
\hline Mean & 3.84 & 79 & 3.94 & 38 & 3.47 & 4.10 & 222 & 4.20 & 158 & 3.49 \\
\hline SD & 0.64 & & 0.63 & & 0.59 & 0.61 & & 0.64 & & 0.51 \\
\hline Middle s & & & & & & & & & & \\
\hline Mean & 4.00 & 320 & 3.98 & 109 & 0.75 & 4.02 & 287 & 4.04 & 131 & 3.45 \\
\hline SD & 0.77 & & 0.85 & & 0.14 & 0.72 & & 0.81 & & 0.57 \\
\hline High sch & & & & & & & & & & \\
\hline Mean & 3.86 & 92 & 3.84 & 76 & 3.38 & 3.99 & 195 & 4.14 & 168 & 3.38 \\
\hline SD & 0.74 & & 0.74 & & 0.47 & 0.83 & & 0.77 & & 0.51 \\
\hline Hopelessn & & & & & & & & & & \\
\hline Upper el & & & & & & & & & & \\
\hline Mean & 74 & 79 & 74 & 38 & 73 & 73 & 222 & 78 & 158 & 73 \\
\hline SD & 14 & & 13 & & 19 & 15 & & 12 & & 19 \\
\hline Middle s & & & & & & & & & & \\
\hline Mean & 75 & 320 & 76 & 109 & 75 & 76 & 287 & 75 & 131 & 80 \\
\hline SD & 14 & & 15 & & 14 & 14 & & 15 & & 12 \\
\hline High sch & & & & & & & & & & \\
\hline Mean & 77 & 92 & 81 & 76 & 79 & 78 & 195 & 77 & 168 & 75 \\
\hline SD & 13 & & 12 & & 14 & 13 & & 14 & & 15 \\
\hline Self-efficac & & & & & & & & & & \\
\hline Upper el & & & & & & & & & & \\
\hline Mean & 3.60 & 79 & 3.64 & 38 & 3.64 & 3.81 & 222 & 3.93 & 158 & 3.87 \\
\hline SD & 0.70 & & 0.65 & & 0.71 & 0.70 & & 0.66 & & 0.74 \\
\hline Middle s & & & & & & & & & & \\
\hline Mean & 3.82 & 320 & 3.79 & 109 & 3.77 & 3.84 & 287 & 3.87 & 131 & 3.87 \\
\hline SD & 0.66 & & 0.71 & & 0.70 & 0.67 & & 0.69 & & 0.81 \\
\hline High sch & & & & & & & & & & \\
\hline Mean & 3.71 & 92 & 3.77 & 76 & 3.86 & 3.85 & 195 & 3.93 & 168 & 3.86 \\
\hline SD & 0.63 & & 0.74 & & 0.78 & 0.71 & & 0.66 & & 0.71 \\
\hline Decision $\mathrm{m}$ & & & & & & & & & & \\
\hline Upper el & & & & & & & & & & \\
\hline Mean & 3.34 & 78 & 3.42 & 37 & 3.34 & 3.49 & 220 & 3.39 & 155 & 3.33 \\
\hline SD & 0.62 & & 0.76 & & 0.51 & 0.64 & & 0.62 & & 0.51 \\
\hline Middle s & & & & & & & & & & \\
\hline Mean & 3.43 & 319 & 3.30 & 109 & 3.34 & 3.46 & 284 & 3.40 & 129 & 3.46 \\
\hline SD & 0.61 & & 0.67 & & 0.58 & 0.61 & & 0.61 & & 0.62 \\
\hline High sch & & & & & & & & & & \\
\hline Mean & 3.45 & 91 & 3.48 & 76 & 3.48 & 3.42 & 193 & 3.48 & 167 & 3.39 \\
\hline SD & 0.60 & & 0.60 & & 0.61 & 0.66 & & 0.63 & & 0.64 \\
\hline
\end{tabular}


Table 2

Means and Standard Deviations for Selected Variables (Continued from previous page)

\begin{tabular}{|c|c|c|c|c|c|c|c|c|c|c|}
\hline \multirow[b]{2}{*}{ Variable } & \multicolumn{5}{|c|}{ Comparison Group } & \multicolumn{5}{|c|}{ Sex Can Wait } \\
\hline & Pretest & $\mathbf{n}$ & Posttest & $\mathbf{n}$ & Follow-up & Pretest & $\mathbf{n}$ & Posttest & $\mathbf{n}$ & Follow-up \\
\hline \multicolumn{11}{|c|}{ Intent to remain abstinent $(1=$ low, $5=$ high $)$} \\
\hline \multicolumn{11}{|c|}{ Upper elementary } \\
\hline Mean & 3.00 & 78 & 3.33 & 35 & 2.70 & 3.55 & 219 & 3.66 & 156 & 3.30 \\
\hline SD & 1.34 & & 1.17 & & 1.28 & 1.17 & & 1.19 & & 1.27 \\
\hline \multicolumn{11}{|c|}{ Middle school } \\
\hline Mean & 3.40 & 316 & 3.40 & 106 & 3.38 & 3.21 & 283 & 3.25 & 129 & 3.54 \\
\hline SD & 1.31 & & 1.28 & & 1.44 & 1.31 & & 1.27 & & 1.32 \\
\hline \multicolumn{11}{|c|}{ High school } \\
\hline Mean & 3.14 & 92 & 2.89 & 76 & 2.61 & 3.25 & 189 & 3.48 & 164 & 3.06 \\
\hline SD & 1.29 & & 1.34 & & 1.35 & 1.33 & & 0.63 & & 1.54 \\
\hline \multicolumn{11}{|c|}{ Ever had sexual intercourse? (percent yes) } \\
\hline \multicolumn{11}{|c|}{ Upper elementary } \\
\hline Mean & 16 & 61 & 36 & 32 & 22 & 5 & 197 & 20 & 153 & 14 \\
\hline SD & 37 & & 48 & & 42 & 22 & & 40 & & 34 \\
\hline \multicolumn{11}{|c|}{ Middle school } \\
\hline Mean & 11 & 281 & 19 & 107 & 27 & 13 & 243 & 24 & 126 & 17 \\
\hline SD & 31 & & 39 & & 45 & 33 & & 43 & & 37 \\
\hline \multicolumn{11}{|c|}{ High school } \\
\hline Mean & 26 & 82 & 45 & 75 & 51 & 13 & 172 & 22 & 166 & 35 \\
\hline SD & 44 & & 50 & & 50 & 34 & & 41 & & 48 \\
\hline \multicolumn{11}{|c|}{ Had sex last 30 days? (percent yes) } \\
\hline \multicolumn{11}{|c|}{ Upper elementary } \\
\hline Mean & 16 & 58 & 31 & 32 & 22 & 3 & 191 & 12 & 152 & 7 \\
\hline SD & 37 & & 47 & & 42 & 36 & & 47 & & 25 \\
\hline \multicolumn{11}{|c|}{ Middle school } \\
\hline Mean & 7 & 219 & 13 & 107 & 21 & 7 & 239 & 12 & 126 & 17 \\
\hline SD & 26 & & 33 & & 41 & 26 & & 34 & & 37 \\
\hline \multicolumn{11}{|c|}{ High school } \\
\hline Mean & 19 & 79 & 29 & 76 & 38 & 7 & 168 & 13 & 163 & 25 \\
\hline SD & 39 & & 46 & & 49 & 25 & & 33 & & 43 \\
\hline
\end{tabular}

the comparison group in regard to knowledge (Table 2) and sexual intercourse in the last month (Table 3). The Sex Can Wait group had a higher level of knowledge and was less likely to report participation in sexual intercourse in the last month.

\section{Middle School Student Outcomes}

Matched pretest-posttest data were obtained from 605 students, and matched pretest-18-month follow-up data were collected from 241 students. The pretest-posttest students included 453 whites (75.9\%), 128 African Americans $(21.4 \%), 5$ Hispanics, (.8\%), 4 Asians $(.7 \%)$, and 7 American Indians (1.2\%). There were 9 students who did not indicate racial/ethnic membership.

At the middle school level, results of the analysis of covariance indicated no statistically significant posttest differences $(p<.05)$ between the Sex Can Wait treatment group and the comparison group (Table 2). At 18month follow-up, there were significant differences $(\mathrm{p}<.05)$ between the Sex Can Wait treatment group and the comparison group in regard to sexual intercourse ever (and sexual intercourse in the last month) (Table 3). The Sex Can Wait group was less likely to report participation in sexual intercourse ever and in the last month.

\section{High School Student Outcomes}

Matched pretest-posttest data were obtained from 287 students, and matched pretest-18-month follow-up data were obtained from 244 students. The pretest-posttest students included 262 whites (91.9\%), 9 African Americans (3.2\%), 6 Hispanics (2.1\%), 2 Asian Americans (.7\%), and 6 American Indians $(2.1 \%)$. There were 2 students who did not indicate racial/ethnic membership.

Results of the pretest-posttest analyses of covariance (Table 3) and logistic regression (Table 4) indicated that at the high school level there were statistically significant differences $(p<.05)$ between the Sex Can Wait treatment group and the comparison group in regard to attitudes supportive of abstinence, intent to remain abstinent, 
sexual intercourse ever, and sexual intercourse in the last month. Students in the Sex Can Wait group evidenced attitudes that were more supportive of abstinence, had greater intentions to remain abstinent, and were less likely to report participation in sexual intercourse, ever and in the last month. At 18-month follow-up, there were differences between the Sex Can Wait treatment group and the comparison group in regard to knowledge and intent to remain abstinent. The Sex Can Wait group scored higher on knowledge and indicated a greater intent to remain abstinent.

\section{DISCUSSION}

The purpose of the study was to evaluate the effects of the Sex Can Wait curriculum series. Results indicated that the upper elementary program produced short-term gains in knowledge, self-efficacy, and a more hopeful outlook, with long-term gains in knowledge and reduced likelihood of participation in sexual intercourse in the last month. At the middle school level, there were no statistically significant short-term benefits, but in long term the program produced gains in knowledge and reduced likelihood of participation in sexual intercourse ever and sexual intercourse in the last month. At the high school level, there were short-term gains in attitudes supportive of abstinence, intent to remain abstinent, and reduced likelihood of sexual intercourse ever and in the last month. The program produced long-term gains in knowledge and intent to remain abstinent.

Relatively few abstinence-only sex education programs have been properly evaluated. Previous evaluations of the
Sex Can Wait curriculum series have found the program to produce gains in knowledge, ${ }^{17,20,21,27}$ life skills, ${ }^{17,27}$ more positive attitudes toward abstinence, ${ }^{17,20}$ enhanced selfesteem, ${ }^{21}$ more conservative attitudes toward sex before marriage, ${ }^{17}$ enhanced decision-making behaviors, greater intent to abstain from sex, ${ }^{18}$ increased parent-child communication regarding sexual issues, ${ }^{17}$ and reduced participation in sexual intercourse. ${ }^{17,18,21}$ This was the first examination of the impact of this curriculum series, however, that included a long-term follow-up. Results showed statistically significant differences at 18 months between the treatment and comparison groups in regard to several variables including sexual behavior variables for both the upper elementary and middle school curricula, and for knowledge and abstinence intent at the high school level. The fact that the high school curriculum showed short-term behavioral benefits but no long-term behavioral benefit suggests that it may be easier for programs to produce a delay in participation in sex among younger adolescents than among older adolescents.

Although the curriculum series did demonstrate a statistically significant effect for several variables, including sexual behavior, in most cases the effect size was modest. This fits Kirby's ${ }^{28}$ analysis of the situation relative to factors that influence teen sexual behavior and teen pregnancy. He observed that there were a number of influences on adolescent sexual behavior and teen pregnancy, but none of them accounted for a substantial amount of the variation in behavior.

The study had several limitations, including the inability to randomly assign schools to treatment and control groups

Table 3

Results of Analysis of Covariance Tests

\begin{tabular}{|c|c|c|c|c|c|c|c|c|}
\hline \multirow[b]{2}{*}{ Level Variable } & \multicolumn{4}{|c|}{ Posttest } & \multicolumn{4}{|c|}{ Follow-up } \\
\hline & df & $\mathbf{F}$ & $\mathbf{p}$ & Eta square & df & $\mathbf{F}$ & $\mathbf{p}$ & Eta square \\
\hline \multicolumn{9}{|l|}{ Upper elementary } \\
\hline Knowledge & 1,298 & 61.17 & .001 & .170 & 1,195 & 11.31 & .001 & .055 \\
\hline Attitudes & 1,298 & 2.75 & .098 & .009 & 1,195 & .75 & .386 & .004 \\
\hline Hopelessness & 1,298 & 11.97 & .001 & .039 & 1,195 & .61 & .435 & .003 \\
\hline Self-efficacy & 1,298 & 7.04 & .008 & .023 & 1,195 & 1.79 & .182 & .009 \\
\hline Decision making & 1,298 & 1.15 & .284 & .004 & 1,191 & .13 & .718 & .001 \\
\hline Abstinent intent & 1,294 & 1.01 & .315 & .003 & 1,191 & 3.56 & .061 & .019 \\
\hline \multicolumn{9}{|l|}{ Middle school } \\
\hline Knowledge & 1,603 & 0.58 & .448 & .001 & 1,240 & .01 & .934 & .000 \\
\hline Attitudes & 1,604 & 0.60 & .438 & .001 & 1,239 & .19 & .660 & .001 \\
\hline Hopelessness & 1,604 & 2.05 & 152 & .003 & 1,239 & 1.90 & .170 & .008 \\
\hline Self-efficacy & 1,604 & 2.17 & .141 & .004 & 1,239 & .59 & .442 & .002 \\
\hline Decision making & 1,600 & 3.07 & .080 & .005 & 1,237 & 1.35 & .246 & .006 \\
\hline Abstinent intent & 1,596 & 0.32 & .572 & .001 & 1,235 & 2.81 & .095 & .012 \\
\hline \multicolumn{9}{|l|}{ High School } \\
\hline Knowledge & 1,284 & 2.63 & .106 & .009 & 1,243 & 11.39 & .001 & .045 \\
\hline Attitudes & 1,287 & 8.50 & .004 & .029 & 1,244 & .70 & .404 & .003 \\
\hline Hopelessness & 1,284 & 7.43 & .007 & .025 & 1,243 & 3.31 & .070 & .014 \\
\hline Self-efficacy & 1,284 & 1.33 & .249 & .005 & 1,244 & .24 & .626 & .001 \\
\hline Decision making & 1,281 & 0.11 & .738 & .000 & 1,243 & 1.73 & .189 & .007 \\
\hline Abstinent intent & 1,278 & 13.31 & .001 & .046 & 1,240 & 3.92 & .049 & .016 \\
\hline
\end{tabular}


and the use of in-house comparison groups. Reliability for the various scales was determined using a measure of internal consistency, rather than a test-retest reliability, and for some of these the alpha was low (.57 for initiation and persistence, .59 for decision making). There are always concerns about the validity of self-report data. There were also some logical inconsistencies in student responses (eg, some students reported having intercourse in the last 30 days but had also reported never having had intercourse).

There was also a sizable group of students who were lost to follow-up. This is a potential threat to the internal validity of the study in that outcomes for the students who were lost to follow-up might have been different from those students for whom data were available.
Additionally, treatment students and comparison students attended the same school. Thus, this design is susceptible to treatment diffusion (comparison group contamination) in 3 ways. First, students may have talked outside of the classroom about the things they were learning, so some students in the comparison groups may have learned from students in the treatment groups. Second, some teachers who taught the Sex Can Wait curriculum also taught the comparison group classes. Although they did not teach the curriculum to comparison group classes, they may have conveyed some of the same attitudes and knowledge to the comparison classes that they did to the Sex Can Wait classes. Third, students from the same schools were more than likely date each other, live in the same neighborhoods, and were affiliated with the same

Table 4

Results of Logistic Regression Tests for Sexual Behavior

\begin{tabular}{|c|c|c|c|c|c|c|c|c|c|}
\hline & \multicolumn{4}{|c|}{ Pretest-Posttest } & \multirow[b]{2}{*}{$\mathbf{n}$} & \multicolumn{4}{|c|}{ Pretest-Follow-up } \\
\hline & $\begin{array}{l}\text { Odds } \\
\text { Ratio }\end{array}$ & $\begin{array}{l}95 \% \text { Confidence } \\
\text { Interval }\end{array}$ & $\mathbf{p}$ & $\begin{array}{c}\text { Cumulative } \\
\mathbf{R}^{2}\end{array}$ & & $\begin{array}{l}\text { Odds } \\
\text { Ratio }\end{array}$ & $\begin{array}{l}95 \% \text { Confidence } \\
\text { Interval }\end{array}$ & $\mathbf{p}$ & $\underset{\mathbf{R}^{2}}{\text { Cumulative }}$ \\
\hline \multicolumn{5}{|c|}{ Sexual intercourse (ever) } & 182 & & & & \\
\hline \multicolumn{10}{|c|}{$\begin{array}{l}\text { Upper elementary } \\
(n=295)\end{array}$} \\
\hline Ever-pre & 1.99 & $1.01-3.91$ & .05 & .04 & & 1.44 & $.49-4.24$ & .51 & .01 \\
\hline Intent-pre & .73 & $.57-.93$ & .01 & .08 & & .87 & $.62-1.23$ & .44 & .02 \\
\hline Group & .73 & $.38-1.38$ & .33 & .09 & & .59 & $.21-1.63$ & .31 & .03 \\
\hline $\begin{array}{l}\text { Middle School } \\
\quad(n=595)\end{array}$ & & & & & 229 & & & & \\
\hline Ever-pre & 4.92 & $3.08-7.86$ & .00 & .18 & & 5.27 & $2.29-12.11$ & .00 & .17 \\
\hline Intent-pre & .67 & $.55-.80$ & .00 & .23 & & .68 & $.51-.91$ & .01 & .21 \\
\hline Group & 1.13 & $.72-1.77$ & .61 & .23 & & .48 & $.23-.98$ & .05 & .23 \\
\hline $\begin{array}{l}\text { High school } \\
\qquad(\mathrm{n}=279)\end{array}$ & & & & & 237 & & & & \\
\hline Ever-pre & 5.04 & $2.54-10.01$ & .00 & .28 & & 2.99 & $1.47-6.09$ & .00 & .13 \\
\hline Intent-pre & .44 & $.32-.60$ & .00 & .39 & & .63 & $.50-.80$ & .00 & .20 \\
\hline Group & .29 & $.15-.58$ & .00 & .44 & & .57 & $.31-1.05$ & .07 & .22 \\
\hline \multicolumn{10}{|l|}{$\begin{array}{c}\text { Sexual intercourse } \\
\text { (last } 30 \text { days) }\end{array}$} \\
\hline $\begin{array}{l}\text { Upper elementary } \\
(n=293)\end{array}$ & & & & & 183 & & & & \\
\hline Ever-pre & 2.04 & $.89-4.69$ & .09 & .08 & & .62 & $.13-3.01$ & .56 & .01 \\
\hline 30 days-pre & 1.66 & $.66-4.19$ & .29 & .09 & & 1.28 & $.19-8.53$ & .80 & .01 \\
\hline Intent-pre & .62 & $.48-.81$ & .00 & .17 & & 1.06 & $.70-1.58$ & .80 & .01 \\
\hline Group & .56 & $.28-1.12$ & .10 & .18 & & .08 & $.03-.23$ & .00 & .24 \\
\hline $\begin{array}{l}\text { Middle school } \\
\quad(\mathrm{n}=595)\end{array}$ & & & & & 226 & & & & \\
\hline Ever-pre & 2.45 & $1.32-4.54$ & .00 & .10 & & 3.63 & $1.26-10.49$ & .02 & .14 \\
\hline 30 days-pre & 2.24 & $1.13-4.44$ & .02 & .12 & & 2.63 & $.71-9.75$ & .15 & .16 \\
\hline Intent-pre & .76 & $.61-.94$ & .01 & .14 & & .77 & $.55-1.08$ & .13 & .17 \\
\hline Group & .92 & $.54-1.55$ & .75 & .14 & & .27 & $.11-.67$ & .00 & .23 \\
\hline $\begin{array}{l}\text { High school } \\
\qquad(\mathrm{n}=279)\end{array}$ & & & & & 236 & & & & \\
\hline Ever-pre & 2.89 & $1.32-6.31$ & .01 & .20 & & 1.54 & $.73-3.26$ & .26 & .07 \\
\hline 30 days-pre & 2.78 & $1.20-6.45$ & .02 & .25 & & 1.92 & $.80-4.61$ & .15 & .10 \\
\hline Intent-pre & .55 & $.39-.77$ & .00 & .31 & & .66 & $.51-.85$ & .00 & .16 \\
\hline Group & .36 & $.18-.75$ & .01 & .34 & & .63 & $.34-1.19$ & .15 & .16 \\
\hline
\end{tabular}


religious organizations. In each case, the effect of the treatment diffusion is to reduce the amount of difference between the treatment and comparison groups, making it more difficult to detect a significant difference between the groups. Thus, any statistically significant results are in spite of treatment diffusion, not because of it.

In spite of the limitations associated with the study, for those interested in abstinence education, these results are encouraging. They should be considered by educators and others interested in programs to help young people postpone sexual involvement.

\section{References}

1. Irvine JM. Talk About Sex: The Battles Over Sex Education in the United States. Berkeley: University of California Press; 2002.

2. Young M. Enhancing research productivity in health education: what, why and how. The AAHE Scholar Lecture, April 2005; Chicago, Ill.

3. Directory of Abstinence Resources. Sioux Falls, SD: Abstinence Clearinghouse; 2003.

4. Christopher FS, Roosa MW. An evaluation of an adolescent pregnancy prevention program: is "just say no" enough? Fam Relat. 1990; 39:68-72.

5. Roosa M, Christopher S. Evaluation of an abstinence-only adolescent pregnancy prevention program: a replication. Fam Relat. 1990; 39:363-367. 1989.

6. Barth R. Reducing the Risk. Santa Cruz, Calif: ETR Publications;

7. Kirby D, Barth RP, Leland N, Fetro JV. Reducing the Risk: impact of a new curriculum on sexual risk-taking. Fam Plann Perspect. 1991; 23(6):253-263.

8. Jorgensen SR. Project Taking Charge: an evaluation of an adolescent pregnancy prevention program. Fam Relat. 1991;40:373-380.

9. Jorgensen SR, Potts V, Camp B. Project Taking Charge: six-month follow-up of a pregnancy prevention program for early adolescents. Fam Relat. 1993;42:401-406.

10. St Pierre TL, Mark MM, Kaltreider DL, et al. A 27-month evaluation of a sexual activity prevention program in Boys and Girls Clubs across the nation. Fam Relat. 1995;44:69-77.

11. Kirby D, Korpi M, Barth RP, Cagampang HH. The impact of the Postponing Sexual Involvement curriculum among youths in California. Fam Plann Perspect. 1997;29(3):100-108.

12. Barnett JE, Hurst CS. Abstinence education for rural youth: an evaluation of the Life's Walk Program. J Sch Health. 2003;73(7):264-268.
13. Jemmott JB III, Jemmott LS, Fong FT. Abstinence and safer sex HIV risk reduction interventions for African American adolescents a randomized controlled trial. JAMA. 1998;279:1529-1536.

14. Gebhart P, Hart S, Young M. Sex Can Wait: An Abstinence-Based Sexuality Curriculum for High School Classrooms. Santa Cruz, Calif: ETR Associates; 1994.

15. Gebhart P, Hart S, Young M. Sex Can Wait: An Abstinence-Based Sexuality Curriculum for Middle School Classrooms. Santa Cruz, Calif: ETR Associates; 1994.

16. Young M, Young T. Sex Can Wait: An Abstinence-Based Sexuality Curriculum for Upper Elementary Classrooms. Santa Cruz, Calif: ETR Associates; 1994.

17. Young M, Core-Gebhart P, Marx D. Abstinence-oriented sexuality education: initial field test results of the Living Smart curriculum. Fam Life Educ. 1992;10(4):4-8.

18. Goldfarb ES, Donnelly J, Duncan DF, et al. Evaluation of an abstinence-based curriculum for early adolescents: first year changes in sex attitudes, knowledge and behavior. North Am J Psychol. 1999;1: 243-254.

19. Young M, Young T. Abstinence: Pick and Choose Activities. Santa Cruz, Calif: ETR Associates; 1996.

20. Denny G, Young M, Spear C. An evaluation of the "Sex Can Wait" abstinence education curriculum series. Am J Health Behav. 1999;23:134-143.

21. Denny G, Young M, Rausch S, Spear C. An evaluation of an abstinence education curriculum series: Sex Can Wait. Am J Health Behav. 2002;26(5):366-377.

22. Kazdin AE, French NH, Unis AS, et al. Hopelessness, depression, and suicidal intent among psychiatrically disturbed children. $J$ Consult Clin Psychol. 1983;51:504-510.

23. Kazdin AE, Rogers A, Colbus D. The Hopelessness Scale for Children: psychometric characteristics and concurrent validity. $J$ Consult Clin Psychol. 1986;54:242-245.

24. Wehmeyer ML, Palmer SB. Factor structure and construct validity of scores on The Hopelessness Scale for Children with students with $\operatorname{cog}$ nitive disabilities. Educ Psychol Meas. 1998;58:661-667.

25. Sherer M, Maddux JE, Mercandante B, et al. The Self-Efficacy Scale construction and validation. Psychol Rep. 1982;51:663-671.

26. Bandura A. Self-efficacy: toward a unifying theory of behavioral changes. Psychol Rev. 1977;84:191-215.

27. Spear C, Young M, Denny G. Field testing of an abstinence-based sexuality education program for upper elementary students. J Health Educ. 1997;28:335-340.

28. Kirby D. Emerging Answers: Research Findings on Programs to Reduce Teen Pregnancy. Washington, DC: The National Campaign to Prevent Teen Pregnancy; 2001. 